\title{
ANALISIS PENDAPATAN DAN EFEKTIVITAS PENYALURAN DANA PENGEMBANGAN USAHA AGRIBISNIS PEDESAAN (PUAP) PADA USAHATANI SAWI
}

\section{INCOME ANALYSIS AND EFFECTIVENESS OF DISTRIBUTION OF RURAL AGRIBUSINESS DEVELOPMENT FUND IN CHINESE CABBAGE FARMING}

\author{
Andika Patria $^{1}$, Siti Masithoh ${ }^{1 \mathrm{a}}$, Wini Nahraeni ${ }^{1}$ \\ ${ }^{1}$ Jurusan Agribisnis, Fakultas Pertanian Universitas Djuanda Bogor \\ Jalan Tol Ciawi No. 1 Kotak Pos 35 Bogor 16720 \\ a'Korespondensi: Siti Masithoh. Telp: 0817404974; E-mail: smasithoh@yahoo.com
}

\begin{abstract}
This study was aimed to know the implementation of PUAP at Gapoktan Rukun Tani, to analyze income of chinese cabbage farming, and to analyze the effects of productions factors on chinese cabbage farming.Descriptive, income, and multiple regression analyses were conducted by using SPSS 16 application. Research conducted in Gapoktan Rukun Tani, Citapen village by taking40samples ofChinese Cabbagefarmers. Results showed that the implementation of PUAP, it was found that PUAP fund was good distributed. The average income of farmers was Rp 20,077,885.77/Ha and income over cash cost was Rp 12,128,388.66/Ha. The income over total cost wasRp 9,724,215.01/Ha. The R/C over cash cost value was 2.53 and the $\mathrm{R} / \mathrm{C}$ over total cost value was 1.94 . Therefore, this chinese cabbage farming was profitable and worth doing. Results of the regression analysis showed that the $\mathrm{R}^{2}$ value was 84.7 and $\mathrm{F}$ value was 19.626 . Factors significantly affecting production included seed, pesticide, land size, and education. Meanwhile, manure, urea, dolomite, labor, amount of loan, farming experience, and age were not found to significantly affect production.
\end{abstract}

Key words: effectiveness, PUAP, fund distribution, chines cabbage farming

\section{ABSTRAK}

Penelitian ini bertujuan untuk mengetahui implementasi penyaluran dana PUAP, menganalisis pendapatan usahatani sawi dan menganalisis faktor-faktor yang mempengaruhi produksi sawi. Analisis yang digunakan adalah analisis deskriptif, analisis usahatani dan analisis regresi linier berganda dengan menggunakan program SPSS 16. Hasil penelitian menunjukkan bahwa implementasi PUAP sudah berjalan dengan baik dilihat dari pelaksanaan penyaluran dana. Berdasarkan analisis usahatani menunjukkan bahwa penerimaan rata-rata yang diperoleh petani sampel adalah $\mathrm{Rp} 20.077 .885,77 / \mathrm{Ha}$ dengan pendapatan atas biaya tunai sebesar Rp 12. 128.388,66/Ha dan pendapatan atas biaya total sebesar Rp 9.724.215,01 /Ha. Nilai R/C atas biaya tunai sebesar 2,53 dan R/C atas biaya total sebesar 1,94 sehingga usahatani sawi menguntungkan dan layak untuk diusahakan. Hasil analisis regresi berganda menunjukkan bahwa nilai $\mathrm{R}^{2}$ sebesar 84,7 dan nilai $\mathrm{F}$ hitung sebesar 19,626. Faktor-faktor yang berpengaruh nyata terhadap produksi sawi di Desa Citapen adalah benih, pestisida, luas lahan dan pendidikan sedangkan faktor yang tidak berpengaruh nyata yaitu pupuk kandang, pupuk urea, dolomit, tenaga kerja, besar pinjaman, pengalaman usahatani dan umur.

Kata kunci : Efektivitas, PUAP, Penyaluran Dana, Pendapatan, Usahatani Sawi. 


\section{PENDAHULUAN}

Permasalahan yang dihadapi dalam usahatani sawi diantaranya adalah kurangnya akses kepada sumber permodalan dan efisiensi penggunaan input produksi yang pada akhirnya akan mempengaruhi pendapatan petani dan produksi sawi yang dihasilkan. Sumber permodalan masih terbatas untuk usaha produksi, belum menyentuh kegiatan pra dan pasca produksi dan sampai saat ini belum berkembangnya lembaga penjamin serta belum adanya lembaga keuangan khusus yang menangani sektor pertanian (Syahyuti, 2007).

Permodalan masih menjadi masalah bagi petani disebabkan oleh sistem perbankan yang kurang peduli kepada petani. Sulitnya persyaratan administrasi untuk memperoleh modal, serta adanya jaminan yang memberatkan petani pada lembaga perbankan yang bersangkutan menyebabkan lembaga perbankan tidak mau mengambil risiko pada usaha kecil. Kebanyakan petani kecil tidak memiliki jaminan yang sesuai dengan persyaratan yang diajukan oleh lembaga perbankan.

Salah satu program pemerintah yang digulirkan untuk memfasilitasi permodalan petani adalah program Pengembangan Usaha Agribisnis Perdesaan (PUAP). Program ini diperuntukan bagi petani anggota gapoktan yang memiliki keterbatasan modal baik petani pemilik, petani penggarap, buruh tani maupun rumah tangga tani.

Salah satu wilayah di Jawa Barat yang mendapat bantuan dana PUAP adalah Desa Citapen, Kecamatan Ciawi, Kabupaten Bogor. Dana PUAP telah diterima pada tahun 2009 dan dikelola oleh Gabungan Kelompok Tani (Gapoktan) Rukun Tani dengan usaha budidaya tanaman, yang salah satunya adalah sawi. Program PUAP seharusnya dapat memberikan dampak positif bagi usahatani sawi karena program ini pada dasarnya memberikan bantuan penguatan modal bagi petani. Oleh karena itu sangat penting untuk meneliti mengenai usahatani sawi yang berbasis pada implementasi program
PUAP (Pengembangan Usaha Agribisnis Pedesaan) dan faktor-faktor yang mempengaruhi produksi.. Penelitian ini bertujuan untuk (1) mengetahui implementasi program PUAP di Gapoktan Rukun Tani, (2) menganalisis tingkat pendapatan usahatani sawi di Gapoktan Rukun Tani dan (3) menganalisis faktorfaktor yang mempengarahui produksi sawi di Gapoktan Rukun Tani.

\section{BAHAN DAN METODE}

Penelitian ini dilaksanakan di Gapoktan Rukun Tani yang berlokasi di Desa Citapen, Kecamatan Ciawi, Kabupaten Bogor. Lokasi penelitian ini ditentukan secara sengaja (purposive) dengan pertimbangan bahwa desa ini telah memperoleh dana PUAP dan telah mengusahakan dan mengembangkan dana pengembangan PUAP untuk kegiatan agribisnis. Selain itu, desa ini merupakan sentra penghasil tanaman hortikultura di Kabupaten Bogor. Kegiatan pengambilan data penelitian dilaksanakan pada bulan Mei-Juni 2013.

Data yang digunakan dalam penelitian ini terdiri atas data primer dan sekunder. Data primer diperoleh melalui kuisioner dan wawancara langsung dengan petani sampel yaitu petani (anggota gapoktan), pengurus gapoktan atau poktan, ketua gapoktan dan Ketua LKM-A (informan kunci). Sampel dalam penelitian ini difokuskan pada petani (anggota gapoktan) yang telah menerima bantuan dana PUAP tahun 2009.

Data yang dikumpulkan berupa identitas petani, profil petani dan keluarga petani, pinjaman kredit, aset usahatani, biaya, produksi usahatani, kegiatan gapoktan, pedum, juklak, juknis PUAP, ketentuan pinjaman PUAP dan RUB, RUK, RUA gapoktan. Data sekunder diperoleh dari instansi terkait meliputi Badan Pusat Statistik (BPS), Departemen Pertanian, Badan Penyuluhan Pertanian, Peternakan dan Kehutanan Kecamatan Ciawi (BP3K), Dinas Pertanian dan Pusat Sosial Ekonomi dan Kebijakan Pertanian (PSEKP). 
Populasi pada penelitian ini adalah petani penerima dana PUAP. Satu gapoktan terdiri atas lima kelompok tani yang anggotanya terdiri atas 236 petani. Penelitian ini mengambil sampel petani yang menerima dana PUAP tahun 2009 dengan karakteristik usahataninya adalah tanaman hortikultura yaitu sawi. Pemilihan sampel petani sawi dengan pertimbangan bahwa sebagian besar anggota gapoktan memiliki usaha bercocok tanam sawi, sehingga dengan adanya karakteristik tersebut akan memudahkan peneliti untuk menentukan dan mengambil sampel. Pengambilan sampel menggunakan metode simple random sampling (acak sederhana). Jumlah seluruh sampel sebanyak 40 petani.

Data yang diperoleh dianalisis secara kualitatif dan kuantitatif. Analisis kualitatif dilakukan dengan analisis deskriptif, sedangkan analisis kuantitatif dilakukan dengan analisis usahatani dan analisis regresi linier berganda menggunakan program SPSS 16.0 serta metode OLS (Ordinary Least Square). Analisis usahatani dilakukan untuk mengetahui tingkat pendapatan petani dan kelayakan usahatani sawi. Pendapatan yaitu selisih antara penerimaan dengan pengeluaran selama periode tertentu. Pendapatan dihitung dengan rumus :

Keterangan :

$$
\mathrm{I}=\mathrm{TR}-\mathrm{TC}
$$

$$
\begin{array}{ll}
\mathrm{I} & =\text { Pendapatan } \\
\mathrm{TR} & =\text { Total Revenue/Penerimaan Total } \\
\mathrm{TC} & =\text { Total Cost } / \text { Biaya Total }
\end{array}
$$

Kelayakan usahatani sawi dilihat dari nilai $\mathrm{R} / \mathrm{C}$ (perbandingan antara penerimaan total dengan pengeluaran total). Analisis R/C dihitung dengan rumus

$$
R / C=\frac{\mathrm{TR}}{\mathrm{TC}}
$$

Analisis regresi linier berganda dilakukan untuk menganalisis faktor-faktor yang mempengaruhi produksi sawi, dengan fungsi (persamaan) regresi :

$Y=a+b_{1} X_{1}+b_{2} X_{2}+b_{3} X_{3}+b_{4} X_{4}+b_{5}$ $\mathrm{X}_{5}+\mathrm{b}_{6} \mathrm{X}_{6}+\mathrm{b}_{7} \mathrm{X}_{7}+\mathrm{b}_{8} \mathrm{X}_{8}+\mathrm{b}_{9} \mathrm{X}_{9}+\mathrm{b}_{10} \mathrm{X}_{10}$ $+b_{11} X_{11}+e$
Keterangan:

$$
\begin{aligned}
& \mathrm{Y}=\text { Produksi Sawi }(\mathrm{Kg}) \\
& \mathrm{X}_{1}=\text { Luas Lahan }(\mathrm{Ha}) \\
& \mathrm{X}_{2}=\text { Tenaga Kerja }(\mathrm{HOK}) \\
& \mathrm{X}_{3}=\text { Benih }(\mathrm{Kg}) \\
& \mathrm{X}_{4}=\text { Pupuk Kandang }(\mathrm{Kg}) \\
& \mathrm{X}_{5}=\text { Pupuk Urea }(\mathrm{Kg}) \\
& \mathrm{X}_{6}=\text { Pestisida (Liter) } \\
& \mathrm{X}_{7}=\text { Dolomit (Kg) } \\
& \mathrm{X}_{8}=\text { Pendidikan (Tahun) } \\
& \mathrm{X}_{9}=\text { Besar Pinjaman (Rp) } \\
& \mathrm{X}_{10}=\text { Pengalaman Usahatani (tahun) } \\
& \mathrm{X}_{11}=\text { Umur (Tahun) } \\
& \mathrm{a}=\text { Konstanta } \\
& \mathrm{b}_{1}, \mathrm{~b}_{2}, \mathrm{~b}_{3} \ldots \mathrm{b}_{11}=\text { Koefisien Regresi } \\
& \mathrm{e} \quad=\text { error term }
\end{aligned}
$$

Dalam penelitian ini variabel yang diduga berpengaruh positif terhadap produksi sawi $(\mathrm{Y})$ adalah luas lahan $\left(\mathrm{X}_{1}\right)$, tenaga kerja $\left(\mathrm{X}_{2}\right)$, benih $\left(\mathrm{X}_{3}\right)$, pupuk kandang $\left(\mathrm{X}_{4}\right)$, pupuk urea $\left(\mathrm{X}_{5}\right)$, pestisida $\left(\mathrm{X}_{6}\right)$, dolomit $\left(\mathrm{X}_{7}\right)$, pendidikan $\left(\mathrm{X}_{8}\right)$, besar pinjaman $\left(\mathrm{X}_{9}\right)$ dan pengalaman usahatani $\left(\mathrm{X}_{10}\right)$. Variabel yang diduga berpengaruh negatif terhadap pendapatan petani adalah $\operatorname{umur}\left(\mathrm{X}_{11}\right)$.

\section{Hasil dan Pembahasan Implementasi Program PUAP (Pengembangan Usaha Agribisnis Pedesaan)}

Salah satu keberhasilan pelaksanaan program PUAP adalah keberhasilan penyaluran dana bantuan tersebut kepada petani anggota gapoktan. Pelaksanaan penyaluran dana PUAP dapat dilihat dari sisi gapoktan sebagai pihak penyalur dan petani sebagai pihak penerima. Berdasarkan kriteria pihak penyalur yakni gapoktan, pelaksanaan penyaluran bantuan PUAP terdiri atas realisasi pinjaman PUAP, jangkauan pinjaman, frekuensi pinjaman, persentase tunggakan.

Pelaksanaan penyaluran dana PUAP di Gapoktan Rukun Tani untuk kegiatan simpan pinjam telah dimulai tahun 2009. Jumlah dana PUAP yang diterima oleh Gapoktan Rukun Tani yaitu sebesar Rp 100.000.000. Ketentuan yang ditetapkan gapoktan yaitu besarnya 
pinjaman yang diterima petani sebesar Rp 500.000 sampai dengan Rp 5.000.000. Realisasi dana PUAP di Gapoktan Rukun
Tani Desa Citapen tahun 2012 dapat dilihat pada Tabel 1.

Tabel 1 Realisasi Dana PUAP di Gapoktan Rukun Tani Desa Citapen Tahun 2012.

\begin{tabular}{ccrrrr}
\hline No & Tahun & \multicolumn{1}{c}{ Modal Awal } & $\begin{array}{c}\text { Modal Yang } \\
\text { digunakan }\end{array}$ & \multicolumn{1}{c}{ Bunga } & \multicolumn{1}{l}{ Jumlah } \\
\hline 1 & 2009 & 100.000 .000 & 40.000 .000 & 720.000 & 100.720 .000 \\
2 & 2010 & 100.720 .000 & 100.250 .000 & 21.654 .000 & 122.374 .000 \\
3 & 2011 & 122.374 .000 & 109.000 .000 & 23.544 .000 & 145.918 .000 \\
4 & 2012 & 145.918 .000 & 141.650 .000 & 30.596 .400 & 176.514 .400 \\
\hline
\end{tabular}

Sumber : Data Gapoktan Rukun Tani (2012), diolah

Jangkauan realisasi pinjaman dana PUAP di Gapoktan Rukun Tani Desa
Citapen tahun 2012 secara umum dapat dilihat pada Tabel 2.

Tabel 2 Jangkauan Realisasi Pinjaman PUAP di Gapoktan Rukun Tani Desa Citapen, 2012.

\begin{tabular}{|c|c|c|c|c|c|}
\hline \multirow{2}{*}{ No } & \multirow{2}{*}{ Tahun } & \multirow{2}{*}{$\begin{array}{c}\text { Realisasi Pinjaman } \\
\text { (Rp) }\end{array}$} & \multicolumn{2}{|c|}{ Jangkauan Kredit (Orang) } & \multirow{2}{*}{ Jumlah } \\
\hline & & & On Farm & Off Farm & \\
\hline 1 & 2009 & 40.000 .000 & 20 & 11 & 31 \\
\hline 2 & 2010 & 100.250 .000 & 38 & 24 & 62 \\
\hline 3 & 2011 & 109.000 .000 & 71 & 34 & 105 \\
\hline 4 & 2012 & 141.650 .000 & 70 & 20 & 90 \\
\hline
\end{tabular}

Sumber : Data Gapoktan Rukun Tani (2012), diolah

Frekuensi pinjaman dana PUAP di Gapoktan Rukun Tani dilakukan sebanyak 3 kali dalam tempo 2 tahun 5 bulan, dengan adanya tiga kali priode penyaluran dana PUAP ke anggota gapoktan, membuat perputaran dana PUAP menjadi cepat, karena adanya pengembalian ditambah dengan jasa yang dibayarkan. Jumlah tunggakan pinjaman dana PUAP di Gapoktan Rukun Tani tahun 2012 dapat dilihat pada Tabel 3.

Tabel 3 Jumlah Tunggakan Pinjaman Dana PUAP di Desa Citapen Tahun 2012.

\begin{tabular}{clrr}
\hline No & \multicolumn{1}{c}{ Waktu(Bulan) } & \multicolumn{1}{c}{$\begin{array}{c}\text { Realisasi } \\
\text { Pinjaman (Rp) }\end{array}$} & $\begin{array}{c}\text { Jumlah } \\
\text { Tunggakan }\end{array}$ \\
\hline 1 & Januari - Februari & 20.500 .000 & 0 \\
2 & Maret - April & 22.000 .000 & 1.100 .000 \\
3 & Mei - Juni & 23.650 .000 & 6.230 .000 \\
4 & Juli - Agustus & 17.000 .000 & 7.400 .000 \\
5 & September - Oktober & 29.000 .000 & 18.650 .000 \\
6 & November - Desember & 29.500 .000 & 25.200 .000 \\
\hline
\end{tabular}

Sumber : Data Gapoktan Rukun Tani (2012), diolah

\section{Pendapatan Usahatani Sawi}

Penerimaan usahatani merupakan nilai yang diperoleh dari produksi total usahatani yang dikelola oleh petani di Gapoktan Rukun Tani pada jangka waktu tertentu. Analisis usahatani sawi yang dilakukan terdiri atas analisis pendapatan serta analisis $\mathrm{R} / \mathrm{C}$ rasio usahatani sawi. Perhitungan pendapatan dan rasio penerimaan usahatani sawi di Desa Citapen per hektar pada tahun 2012 dapat dilihat pada Tabel 4. 
Tabel 4 Perhitungan Pendapatan dan Rasio Penerimaan Terhadap Biaya (R/C) Usahatani Sawi di Desa Citapen Per Hektar Tahun 2012.

\begin{tabular}{|c|c|c|c|c|c|}
\hline No & Uraian & Jumlah & Harga & Nilai & $\%$ \\
\hline \multirow[t]{4}{*}{1} & Penerimaan & & & & \\
\hline & Produksi Total (Kg) & $12.453,98$ & & & \\
\hline & Harga (Rp) & & $1.611,76$ & & \\
\hline & Penerimaan (Rp) & & & $20.072 .885,77$ & \\
\hline \multirow[t]{15}{*}{2} & Biaya Tunai & & & & \\
\hline & a. Benih (Kg) & 1,39 & $100.000,00$ & $139.000,00$ & 1,34 \\
\hline & b. Pupuk (Kg) & & & & \\
\hline & - Pupuk Kandang & $4.732,49$ & 800,00 & $3.785 .992,00$ & 36,58 \\
\hline & - Pupuk Urea & 187,66 & $1.800,00$ & $337.788,00$ & 3,26 \\
\hline & c. Pestisida & & & & \\
\hline & - Antracol (Kg) & 10,08 & $100.000,00$ & $1.008 .000,00$ & 9,74 \\
\hline & - Curacorn (Liter) & 9,84 & $22.000,00$ & $216.480,00$ & 2,09 \\
\hline & - Gandasil (Kg) & 1,10 & $60.000,00$ & $66.000,00$ & 0,64 \\
\hline & d. Dolomit $(\mathrm{Kg})$ & $1.995,00$ & 500,00 & $997.500,00$ & 9,64 \\
\hline & e. Tenaga Kerja & & & & \\
\hline & - TKLK Pria (HOK) & 30,15 & $25.000,00$ & $753.750,00$ & 7,28 \\
\hline & - TKLK Wanita (HOK) & 6,51 & $15.000,00$ & $97.650,00$ & 0,94 \\
\hline & F. Biaya Lain-lain & & & $542.337,11$ & 5,24 \\
\hline & Jumlah Total Biaya Tunai & & & 7.944.497,11 & \\
\hline \multirow[t]{7}{*}{3} & Biaya diperhitungkan & & & & \\
\hline & a. Penyusutan Alat & & & $287.132,47$ & 2,77 \\
\hline & b. Tenaga Kerja & & & & \\
\hline & - TKDK Pria (HOK) & 8,65 & $25.000,00$ & $216.250,00$ & 2,09 \\
\hline & - TKDK Wanita (HOK) & 3,19 & $15.000,00$ & $47.850,00$ & 0,46 \\
\hline & c. Sewa Lahan & & & $1.852 .941,18$ & 17,91 \\
\hline & $\begin{array}{l}\text { Jumlah Total Biaya } \\
\text { diperhitungkan }\end{array}$ & & & $2.404 .173,65$ & \\
\hline 4 & Jumlah Biaya Total & & & $10.348 .670,76$ & 100,00 \\
\hline 5 & Pendapatan Atas Biaya Tunai & & & $12.128 .388,66$ & \\
\hline 6 & Pendapatan Atas Biaya Total & & & $9.724 .215,01$ & \\
\hline 7 & R/C Biaya Tunai & & & 2,53 & \\
\hline 8 & R/C Biaya Total & & & 1,94 & \\
\hline
\end{tabular}

Sumber : Data Primer, diolah

Berdasarkan Tabel 4 komponen biaya produksi terbesar yang dikeluarkan oleh petani adalah biaya pupuk sebesar $39,84 \%$ dari biaya total. Pengeluaran untuk pupuk kandang adalah sebesar Rp 3.785.992 atau 36,58\%, sedangkan pupuk urea sebesar Rp 337.788 atau 3,26\%. Penggunaan pupuk yang tinggi pada lokasi peneletian bertujuan meningkatkan kesuburan tanah pada lahan produksi agar tanaman sawi dapat tumbuh secara maksimal. Biaya produksi terbesar kedua adalah biaya untuk sewa lahan yaitu sebesar Rp 1.852.941,18 atau 17,91\% dari total biaya. Biaya sewa lahan termasuk ke dalam biaya diperhitungkan karena petani responden memiliki lahan sendiri untuk melakukan kegiatan usahataninya.

Komponen biaya produksi terbesar ketiga adalah biaya untuk pestisida yang digunakan sebagai tindakan pencegahan dan pengobatan terhadap hama dan penyakit tanaman. Biaya yang harus dikeluarkan untuk pestisida sebesar 12,47 
$\%$ dari biaya total. Pestisida yang digunakan terdiri atas Antracol, Curacorn dan Gandasil. Biaya yang harus dikeluarkan untuk pestisida Antracol adalah sebesar Rp 1.008.000 atau 9,74\%, biaya untuk Curachorn adalah sebesar Rp 216.480 atau 2,09 \% dan biaya untuk Gandasil adalah sebesar Rp. 66.000 atau $0,64 \%$. Ketersediaan dana bagi obatobatan harus selalu tersedia, karena tindakan pencegahan dan pengobatan terhadap serangan hama dan penyakit harus dilakukan sesegera mungkin untuk mencegah agar tanaman lain yang sehat tidak tertular.

\section{Faktor-faktor yang Mempengaruhi Produksi Sawi}

Model regresi linier berganda digunakan untuk menganalisis variabelvariabel yang mempengaruhi produksi sawi. Hasil pendugaan koefisien regresi dapat dilihat pada Tabel 5.

Tabel 5 Hasil Pendugaan Koefesien Regresi Usahatani Sawi di Desa Citapen, 2012

\begin{tabular}{|c|c|c|c|c|c|}
\hline Model & Koefisien Regresi & Std. Error & t hit & Signifikansi & VIF \\
\hline (Constant) & 1388.978 & 3017.095 & 0.460 & 0.648 & \\
\hline Luas Lahan & $6780.432 * * * *$ & 2245.388 & 3.910 & 0.000 & 8.518 \\
\hline $\begin{array}{l}\text { Jumlah Tenaga } \\
\text { Kerja }\end{array}$ & 6.409 & 16.636 & 0.385 & 0.702 & 1.740 \\
\hline Benih & $3974.711 * * * *$ & 1105.330 & 3.596 & 0.001 & 4.132 \\
\hline $\begin{array}{l}\text { Jumlah Pupuk } \\
\text { Kandang }\end{array}$ & -0.405 & 0.448 & -0.904 & 0.371 & 2.159 \\
\hline Pupuk Urea & -1.815 & 10.664 & -0.170 & 0.866 & 2.820 \\
\hline Pestisida & $-37.413 * * *$ & 14.744 & -2.538 & 0.015 & 2.837 \\
\hline Dolomit & 0.021 & 1.467 & 0.014 & 0.989 & 3.049 \\
\hline $\begin{array}{l}\text { Tingkat } \\
\text { Pendidikan }\end{array}$ & $-321.544 *$ & 199.416 & -1.612 & 0.115 & 1.369 \\
\hline $\begin{array}{l}\text { Besarnya } \\
\text { Pinjaman }\end{array}$ & 0.001 & 0.001 & 0.887 & 0.381 & 1.527 \\
\hline $\begin{array}{l}\text { Pengalaman } \\
\text { Usahatani }\end{array}$ & -23.507 & 56.834 & -4.414 & 0.681 & 1.574 \\
\hline Umur & 7.275 & 33.910 & 0.215 & 0.831 & 1.502 \\
\hline $\begin{array}{l}\mathrm{R}^{2} \\
\text { F-Hitung }\end{array}$ & & & & & $\begin{array}{r}0,847 \\
19,626\end{array}$ \\
\hline
\end{tabular}

Sumber : Data Primer (diolah).

* nyata pada taraf $85 \%(\alpha=0,15), * * *$ nyata pada taraf $95 \%(\alpha=0,05)$

**** nyata pada taraf $99 \%(\alpha=0,01)$

Berdasarkan Tabel 5 terlihat bahwa pengaruh masing-masing variabel faktor produksi terhadap produksi sawi, maka didapat fungsi sebagai berikut :

$Y=1388,978+6780,432 X_{1}+$
$6,409 X_{2}+3974,711 X_{3}-0,405 X_{4}-$
$1,815 X_{5}-37,413 X_{6}+0,021 X_{7}-$
$321,544 X_{8}+0,0018 X_{9}-23,507 X_{10}+$
$7,275 X_{11}$

Berdasarkan hasil pendugaan menggunakan analisis regresi berganda, diperoleh variabel yang bertanda positif yaitu benih, dolomit, tenaga kerja, luas lahan, besarnya pinjaman dan umur, sedangkan variabel yang bertanda negatif yaitu pupuk kandang, pupuk urea, pestisida, pengalaman usahatani dan pendidikan. Besarnya keragaman dapat ditunjukkan oleh besarnya nilai koefisien determinasi $\left(\mathrm{R}^{2}\right)$. Nilai dari koefisien determinasi berganda $\left(\mathrm{R}^{2}\right)$ sebesar 0,847 atau $84,7 \%$. Ini berarti keragaman produksi sawi dapat dijelaskan oleh variabel luas lahan, tenaga kerja, jumlah benih, jumlah pupuk kandang, pupuk urea, pestisida, 
dolomit, tingkat pendidikan, besar pinjaman, pengalaman usahatani dan umur. Sisanya $15,3 \%$ dapat diterangkan oleh variabel lain yang tidak dimasukan ke dalam model. Variabel lain yang diduga mempengaruhi produksi sawi adalah akses penyuluhan, jumlah tanggungan keluarga dan akses kredit.

Hasil uji $\mathrm{F}$ hitung menunjukkan hasil sebesar 19,626 dan model nyata pada taraf $\alpha=0,05$ persen atau nyata pada selang kepercayaan 95 persen. Hal ini berarti secara bersama-sama variabel bebas yaitu luas lahan, tenaga kerja, jumlah benih, jumlah pupuk kandang, pupuk urea, pestisida, dolomit, tingkat pendidikan, besar pinjaman, pengalaman usahatani dan umur berpengaruh nyata terhadap produksi sawi. Hasil uji secara sendiri-sendiri (uji t) menghasilkan variabel bebas yang nyata secara statistik. Variabel yang berpengaruh nyata yaitu benih, pestisida, luas lahan dan pendidikan. Variabel yang tidak berpengaruh nyata yaitu pupuk kandang, pupuk urea, dolomit, tenaga kerja, besar pinjaman, pengalaman usahatani dan umur.

\section{KESIMPULAN DAN IMPLIKASI KEBIJAKAN}

Kesimpulan :

1. Implementasi PUAP di Gapoktan Rukun Tani Desa Citapen sudah berjalan baik, dilihat dari pelaksanaan penyaluran bantuan PUAP (reliasi pinjaman PUAP, jangkauan pinjaman, frekuensi pinjaman, persentase tunggakan).

2. Berdasarkan analisis pendapatan usahatani sawi dapat disimpulkan bahwa analisis usahatani sawi layak dilakukan $(\mathrm{R} / \mathrm{C}=$ 1,94), penerimaan total sebesar $\mathrm{Rp}$ 20.072.885,77/Ha, biaya total sebesar Rp $10.348 .670,76 / \mathrm{Ha}$ dan pendapatan total sebesar Rp 9.724.215,01.

3. Berdasarkan analisis regresi berganda menunjukkan bahwa variabel yang berpengaruh nyata terhadap produksi sawi yaitu luas lahan, benih, pestisida dan pendidikan sedangkan besarnya pinjaman dana PUAP tidak berpengaruh nyata terhadap produksi sawi.

\section{Implikasi Kebijakan :}

Jumlah produksi sawi di Desa Citapen belum sesuai dengan yang diharapkan oleh gapoktan. Maka dari itu, jumlah pinjaman dana PUAP di Gapoktan Rukun Tani harus dinaikan agar produksi sawi dapat sesuai dengan yang diharapkan.

\section{Daftar Pustaka}

Departemen Pertanian. 2009. Petunjuk Teknis Verifikasi Dokumen Pengembangan Usaha Agribisnis Pedesaan (PUAP). Jakarta.

Departemen Pertanian. 2010. Pedoman Umum Pengembangan Agribisnis Pedesaan (PUAP). Jakarta.

Mangkuatmodjo S. 2004. Statistika Lanjutan. Jakarta: PT Rineka Cipta.

Naibaho T. 2012. Pengaruh Faktor Sosial Ekonomi Petani Terhadap Produksi Usahatani Sawi [Skripsi]. Universitas Sumatera Utara. http://repository.usu.ac.id/[7

September 2013].

Riduwan S. 2007. Pengantar Statistika untuk Penelitian : Pendidikan, Sosial, Komunikasi, Ekonomi dan Bisnis. Bandung: ALFABETA.

Rivai RS, Suradisastra K, Swastika DKS, Noekman KM, Wahyuni S, Sinuraya JF, Agustin NK, Supriyatna Y, Hestina J, Marisa Y dan Wiryono B. 2010, Evaluasi dan Penyusunan Desa Calon Lokasi Pengembangan PUAP. Laporan Akhir. Pusat Sosial Ekonomi dan Kebijakan Pertanian.Badan Penelitian dan Pengembangan Pertanian. Kementrian Pertanian.

Supranto. 2004. Analisis Multivariat: Arti dan Interpretasi. Jakarta: PT Rineka Cipta.

Suratiyah. 2008. Ilmu Usahatani. Jakarta: Penebar Swadaya.

Syahyuti. 2007. Kebijakan Pengembangan Gabungan Kelompok Tani (Gapoktan) Sebagai Kelembagaan Ekonomi dipedesaan. Jurnal Analisis Kebijakan Pertanian (Maret): 15-3 